\title{
Hair Follicle Neoplasm
}

National Cancer Institute

\section{Source}

National Cancer Institute. Hair Follicle Neoplasm. NCI Thesaurus. Code C7367.

A benign or malignant neoplasm arising from the hair follicle. 